\title{
Odour Impact Determination of a Communal Toilet: Field Measurement with Panellists Using Dynamic Plume Method and Dispersion Modelling
}

\author{
Kobina Afful ${ }^{1 *}$, Sampson Oduro-Kwarteng1, Eric Ofosu Antwi², Esi Awuah² \\ ${ }^{1}$ Department of Civil Engineering, Kwame Nkrumah University of Science and Technology, Kumasi, Ghana \\ ${ }^{2}$ University of Energy and Natural Resource, Sunyani, Ghana \\ Email:"affulkobina@yahoo.com,sokwarteng@yahoo.com
}

Received 16 December 2015; accepted 6 March 2016; published 9 March 2016

Copyright @ 2016 by authors and Scientific Research Publishing Inc.

This work is licensed under the Creative Commons Attribution International License (CC BY).

http://creativecommons.org/licenses/by/4.0/

(c) (i) Open Access

\begin{abstract}
In this study, downwind odour concentrations from a communal toilet facility were measured by trained human receptors using the plume method over a 10 day period from mid-May to mid-June 2015 over an approximate downwind area of $1000 \mathrm{~m}^{2}$ (about $800 \mathrm{~m}$ long and $30 \mathrm{~m}$ ). Source emission measurements and extensive meteorological data were collected along with the field odor concentration measurements. Modelling of the measurement events at specific receptor locations using the US EPA SCREEN3 model was compared to field odor measurements at the same locations. The study also showed how subjectivity in the use of the human nose in measuring odour strength could be reduced by selecting odour inspectors using the "Standard Procedure for Testing Individual Odour Sensitivity". Also an odour dispersion model using the US EPA SCREEN3 model was built and simulated and the output of the simulated model compared with the measured data. A paired $t$-test, $t(5)=-1.29, p=0.902(p>0.05)$, showed that there was no statistically significant difference between simulated model output and measured data, hence the possible of using odour dispersion models improved operation of a communal toilet in relation to odour impact.
\end{abstract}

\section{Keywords}

Odour, Dynamic Plume Method, Field Olfactometry

${ }^{*}$ Corresponding author.

How to cite this paper: Afful, K., Oduro-Kwarteng, S., Antwi, E.O. and Awuah, E. (2016) Odour Impact Determination of a Communal Toilet: Field Measurement with Panellists Using Dynamic Plume Method and Dispersion Modelling. Open Journal of Air Pollution, 5, 1-9. http://dx.doi.org/10.4236/ojap.2016.51001 


\section{Introduction}

It is generally recognised that for effective odour control measures to be implemented, the problem must first be quantified [1]-[3]. Such quantification of the problem allows designers and caretakers to make informed decisions on the choice of processes, process modifications or the scope of odour control schemes [4]. The minimisation of odour emissions is becoming one of the most significant challenges and any treatment technology with noticeable odours outside its boundary fence is likely to receive complaints at some time [5]. The control of odour emissions has become an important consideration in the design of new technologies and improvement of existing ones. Given the progressive nature of legislation concerning environmental pollution, it is not unreasonable to expect future legislation targeted at odour emissions.

Increasing access to sanitation is part of the Millennium Development Goal number seven on Environmental Sustainability and has become a top priority for many low-income countries, where no or poor sanitation adds to a substantial burden of diseases and reduces quality of life. But many sanitation programmes have failed to convince people to invest in and use sanitation facilities, especially latrines [6]. Studies from various parts of the developing world have highlighted several barriers to latrine adoption including high cost, dependency on subsidies, poor installation and maintenance, cultural unacceptability, and inadequate cultural involvement [7]. A substantial body of evidence is now available on a complex of behavioural motivators determining use and investments in latrines, for example in the studies of Jenkins and Curtis [8] and Jenkins and Scott [9] from Ghana. A small body of literature has highlighted the issue of disgust, while van der Geest [10] has conducted anthropological studies of toilet behaviour, and argues that taboos, rituals, myths and aesthetics in particular are fundamental issues to understanding defecation behaviour and latrine preference. But few authors have published work on the specific sensors aspect of smell in relation to sanitation promotion [6].

Characterizing odour at source alone is not sufficient to account for the effective impact of odours on citizens, which will require quantifying odours directly at receptors. However, despite a certain simplicity of odour measurement at the emission source, odour measurement in the field is a quite more complicated task. This is one of the main reasons for the spreading of odour impact assessment approaches based on odour dispersion modelling [11]. Currently, just a very limited number of reports discussing the use of tracer gas dispersion experiments both in the field and in wind tunnels for model validation purposes can be found in literature [11]. However, when dealing with odour emissions, it is not always possible to identify a limited number of tracer compounds, nor to relate analytical concentrations to odour properties, thus giving that considering single odorous compounds may be insufficient to account for effective odour perception [11]. For these reasons, the possibility of measuring of odours in the field, both as a way for directly assessing odour annoyance or for verifying that modelled odour concentrations correspond to the effective odour perception by humans, is still an important objective [11].

\section{Materials and Methods}

\subsection{Description of Study Site}

The study was carried out at a communal toilet in Ayigya Zongo, an urban poor community (slum) within the Oforikrom Sub metro of Kumasi Metropolis of Ghana. This communal toilet is a dry toilet with sixteen privy rooms (eight for males and eight for females). The vault which is partially offset from the privy room is fitted with sixteen $100 \mathrm{~mm}$ diameter PVC vent pipes of $3 \mathrm{~m}$ height equally spaced and centrally placed behind each privy room.

\subsection{Selection of Field Measurement Panelists-Nasal Chemosensory Performance}

Odour screening was conducted using the Odour Pen Kit (from St. Croix Sensory, Inc), which is a commercially available method for measuring the olfactory sensitivity. The Odour Pen Kit contains one set of "Sniffing Sticks", a blindfold for the test individual, and odourless non-latex gloves for the test administrator. The "Sniffing Sticks” pens are felt tip markers in which the pen is impregnated with an odour agent. The odour agent used for olfactory threshold screening is n-butanol. Fourteen pens contain the n-butanol solution at different concentrations and two pens are odourless. The "Sniffing Sticks" manufacturer performed the preparation of the test solutions of n-butanol.

All test individuals were tested following the same procedure. The procedure is called the "Standard Proce- 
dure for Testing Individual Odour Sensitivity”. The objective is to identify the detection threshold of the test individual by correct detection of the odour pen in a triad. The presentation method of the odour pens is a triangular force choice method, also known as 3-Alternative Forced Choice (ASTM, 1997). A pen triad is made up of three pens, two are blank pens and a third is an odour pen. The test individual is required to distinguish between the three pens by declaring which pen contains an odour. If no odour is perceived, the test individual is to assign a response of guess to one of the three odour pens. After a response is made, the test proceeds to the next pen triad. The next triad contains an odour pen with a greater n-butanol concentration than the previous series. The logic of the test is that the potential for the test individual to identify the odour pen increases as the test moves to the next concentration level. The increasing concentration levels will continue until the test individual correctly identifies the odour pen in a triad for two test levels. The level where a pen is first correctly identified as the odour pen is the score for the test individual and thus the odour threshold score of the individual. The odour sensitivity score for each of the participants was calculated by averaging the odour pen number (concentration level) associated with their first correct detection of the n-butanol pen in the triad. The odour pens were sorted and presented in ascending concentrations of n-butanol. The concentration values of the odour pens is undetermined, therefore, quantitative n-butanol values are not available.

The Odour Inspector study group was made up graduating class of selected undergraduate students of Kwame Nkrumah University of Science and Technology. One test administrator was used throughout the study. The test administrator learned the test method as described by the Standard Procedure. There was no consideration given to the age or sex of the Odour Inspector tested in the study. A total of ten odour inspectors were assessed for their odour detection threshold. Each inspector was tested five times on five different days (once a week) over a period of one month. A one sample t-test with a test value of 9.5 (mean odour threshold of field supervisor) was carried out to select inspectors for the study.

\subsection{Field Measurements}

The Dynamic Plume Method of field odour measurement was used in this study. The plume determines the extent of the downwind odour plume, under defined meteorological conditions. The measurement team comprised of a field supervisor, two trained odour inspectors and GPS assistant. The two odour inspectors each contributed approximately equal shares of the measurement results while the GPS assistant picked coordinates of various locations where odour is measured. A measurement cycle consisted averagely of 50 single measurements, from which an average of 20 transition points (absence to presence) were determined. The maximum plume reach was determined from the observations obtained during two crossings, one of which including atleast one odour presence point observation and another crossing where only absence point observation are recorded.

The measurements were carried out over a period of one month, thus from mid-May to mid-June 2015, but not every day of the month. Measurements were carried out for 3 days in the first and second weeks and 2 days in the third and fourth weeks. This was done to protect inspectors from odour fatigue. Measurements were also deliberately carried out under a variety of weather conditions and during varying times of the day. No readings were taken at night because the security of the field team and equipments could not be guaranteed.

\subsubsection{Odour Strength Measurement}

The Nasal Ranger Equipment was used for odour strength measurement. Nasal Ranger olfactometers used in this study were provided by the manufacturer, St. Croix Sensory, Inc. They were calibrated by the manufacturer at the beginning of the monitoring period. During the monitoring season, routine maintenance of the equipment was the responsibility of the field supervisor, who inspected the equipment regularly and changed the air filters and the O-rings according to the manufacturer's recommended schedule.

\subsubsection{GPS Data}

The location of the facility and the observation points was coordinated using GPS referenced to the WGS84 datum. A dual frequency GPS device was used to pick the precise location of the toilet facility. A hand-held GPS device with a precision of $\pm 1 \mathrm{~m}$ was used to locate where the dial readings were taken with respect to a particular direction. The data was then transformed to fit into the local coordinate system (Ghana Grid) using Franson CoordTrans. A map of the parcel was produced from the data using AutoCAD Civil 3D 2014. The daily dial readings with their respective location were also plotted unto the map. Contours were generated using the dial 
readings used in place of the elevation of the point to show points of equal dial readings (smell) within a particular time within an interval of 50 dial readings. A plume was defined based on the direction of the wind at the time range of observation.

\subsubsection{Weather Data}

Weather conditions were recorded using a Kestrel ${ }^{\circledR} 4500$ Pocket Weather ${ }^{\circledR}$ Tracker. Data collected included the wind speed, wind direction, relative humidity, and temperature. Weather data were collected each day at each site. Data stored on the Kestrel ${ }^{\circledR} 4500$ Pocket Weather ${ }^{\circledR}$ Tracker is downloaded via bluetooth into MS Excel. Analysis was carried out using SPSS Version 20.0. Regression analyses of odour strength measured (dependent variable) and meteorological data (independent variables) were done. These analyses included the effect of different meteorological variables on odour strength.

\subsection{Field Olfactometry Measurement}

The Nasal Ranger ${ }^{\circledR}$ Field Olfactometer, a nasal organoleptic instrument which directly measures and quantifies odor strength in the ambient air using the Operating Principle of mixing odorous ambient air with odor-free filtered air in discrete volume ratios was used. The discrete volume ratios are called "Dilution-to-Threshold" ratios (D/T ratios). The odour inspector's nose is placed firmly inside the nasal mask against the replaceable "comfort seal". The inspector inhales at a flow rate of 16 - $20 \mathrm{lpm}$ which is within the factory calibrated flow rate range through the nasal mask while standing at rest. The nasal mask has an outlet for exhaled air to exhaust downward. Therefore, the user inhales through the Nasal Ranger and exhales downward through the outlet check valve (St. Croix Sensory Nasal Ranger Field Olfactometer-Operation Manual, 2008).

\subsection{Development and Application of the Odour Dispersion Model}

For air dispersion analysis, the US EPA SCREEN3 model (USEPA, 1995a) was employed. This is a screening version of the ISC3 model was used to simulate the dispersion of odour into the atmosphere. SCREEN3 is a single source Gaussian plume model which provides maximum ground-level concentrations for point, area, flare, and volume sources, as well as concentrations in the cavity zone, and concentrations due to inversion break-up and shoreline fumigation. The dispersion model requires parameterisation for the dimensions of the emission source and the emission velocity or rate.

\section{Model Input and Assumptions}

Several simplifying and limiting assumptions are made in performing the modelling: 1) the particles displayed a Gaussian distribution in both lateral (crosswind) and vertical directions; 2) no gravitational deposition is assumed; 3) the source was assumed to be continuous; 4) the wind velocity and direction were the average measured over the period of measurement and kept constant over the modelled time and distance; 5) the modelled surface was relatively flat; 6 ) the gravitational settling of particles was assumed to be negligible; 7) the particle and wind velocity were assumed to be the same. The results must be viewed in the light of these substantial simplifications and methodological constraints (Taha, et al., 2006).

Model inputs and various assumptions made in building the model based on observations made in the field are presented in Table 1.

\section{Results and Discussions}

\subsection{Nasal Chemosensory Performance}

The olfactory detection threshold of the Odor Inspectors varied. The mean scores of the individuals ranged from 8.3 to 9.4 , with a mean of $8.62\left(n=10, s^{2}=1.27\right)$. No mean scores were distributed between 2 to 5 and 12 to 15 . The mean odour detection threshold of inspectors is shown in Figure 1. The mode of the Odor Inspector group was odor pen 9. The frequency of detection scores followed a normal distribution and was dispersed roughly in the middle of the odor pen range and spread across six pens (pen level $=6-11$ ). The mean odour detection threshold for frequency of scores was dispersed towards the left of the threshold range. Results of the t-test (shown in Table 2) with a test value of 9.5 (the mean odour detection threshold of the field supervisor) shows that there was no statistically significant difference between the odour threshold of 3 (thus inspectors 1, 3 and 
Table 1. Model inputs and assumptions made.

\begin{tabular}{|c|c|c|c|}
\hline Input Parameter & Comment and Assumptions & Value & Unit \\
\hline Source Type & $\begin{array}{l}\text { Area source: It was assumed that emissions from } \\
\text { the source are spread over an area }\end{array}$ & 3 & $\mathrm{~m}^{2}$ \\
\hline Dispersion Coefficient & $\begin{array}{l}\text { Urban: The land use has more than } 50 \% \text { of the surrounding area with } \\
\text { residential buildings and various commercial activities and also with } \\
\text { a population density greater than } 750 \text { people } / \mathrm{m}^{2}\end{array}$ & $>750$ & people $/ \mathrm{m}^{2}$ \\
\hline Emission Rate & $\begin{array}{c}\text { Emission Rate }=\mathrm{C}_{\text {od }} \times \mathrm{V}_{\text {air }} \\
\text { where } \mathrm{C}_{\text {od }} \text { is measured odour concentration }\left(\mathrm{ou} / \mathrm{m}^{3}\right) \\
\mathrm{V}_{\text {air }} \text { is mean speed of air at exit of vent }(\mathrm{m} / \mathrm{s})\end{array}$ & 17,600 & $\mathrm{ou} / \mathrm{m}^{2} / \mathrm{s}$ \\
\hline Source Release Height & The average height of the vent pipes & 3 & $\mathrm{~m}$ \\
\hline Receptor Height & This was set as the average height of the field odour inspectors & 1.7 & $\mathrm{~m}$ \\
\hline $\begin{array}{l}\text { Wind Direction } \\
\text { Relative to Long } \\
\text { Dimension }\end{array}$ & Measured wind direction with the highest frequency & 247.5 & degrees \\
\hline Terrain Option & $\begin{array}{l}\text { Simple flat terrain: This was chosen because terrain } \\
\text { heights do not exceed stack base elevation }\end{array}$ & - & \\
\hline
\end{tabular}

Table 2. Results of One sample t-test for the selection of odour inspectors.

\begin{tabular}{ccccc|}
\hline Inspector & $\mathbf{t}$ & $\mathbf{D f}$ & Sig. (2-tailed) & Comment \\
\hline $\mathbf{1}$ & -1.714 & 9 & 0.121 & Accept \\
$\mathbf{2}$ & -3.254 & 9 & 0.010 & Reject \\
$\mathbf{3}$ & -.327 & 9 & 0.751 & Accept \\
$\mathbf{4}$ & -2.310 & 9 & 0.046 & Reject \\
$\mathbf{5}$ & -4.125 & 9 & 0.003 & Reject \\
$\mathbf{6}$ & -2.577 & 9 & 0.030 & Reject \\
$\mathbf{7}$ & -2.539 & 9 & 0.032 & Reject \\
$\mathbf{8}$ & -2.683 & 9 & 0.025 & Reject \\
$\mathbf{9}$ & -5.622 & 9 & 0.000 & Reject \\
$\mathbf{1 0}$ & -1.724 & 9 & 0.119 & Accept \\
\end{tabular}

Mean Odour Detection Threshold of Inspectors

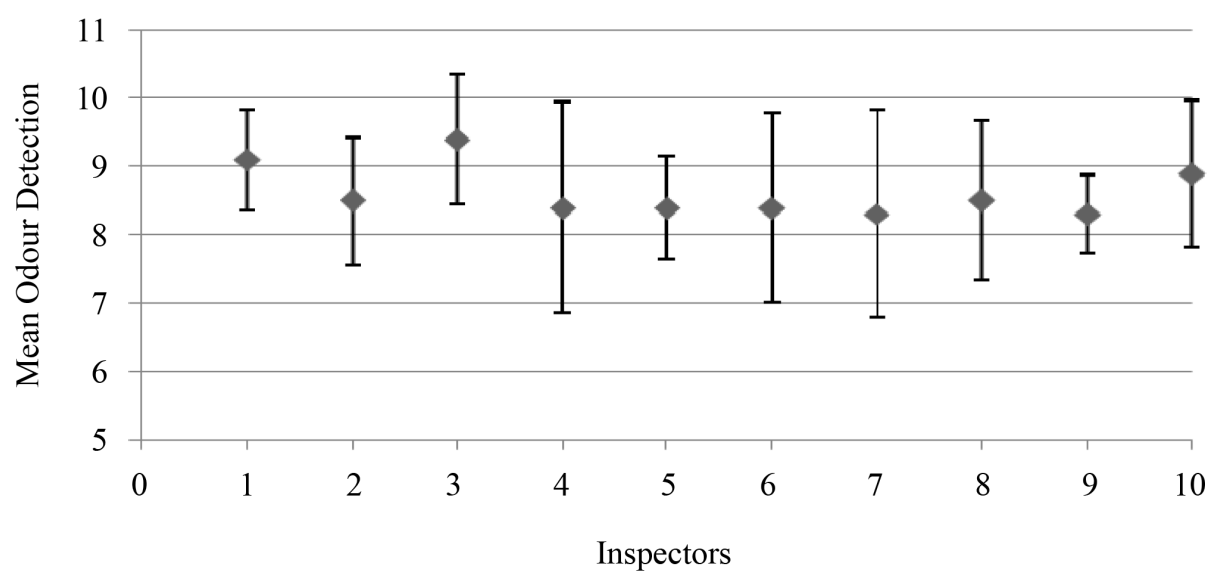

Figure 1. Mean odour detection threshold of inspectors. 
10) out of the 10 inspectors and the field supervisor. However inspectors 1 and 3 were selected since they had a smaller standard deviation as compared to inspector 10

Results bring to fore how subjectivity can be reduced in using the human nose for objective odour studies (calibration of the human nose). Simply measuring one or more individual constituents that may be contributing to the perception of an odour can lead to an incomplete picture of the odour impact to a human observer, as odour plumes from toilet facilities may contain numerous of odorous compounds [12]. Unlike analytical instrumentation, which is capable of separately analyzing emission constituents, the human nose integrates the odors of the various constituents, combining the myriad compounds from an odor source into a unitary odour percept, which can then be quantified as to intensity. The use of resident observers to monitor odour events [13], although practical and inexpensive, has additional drawbacks which include lack of quality control for the data (i.e., no sensitivity calibration, no objective odour detection measurement).

\subsection{Meteorological Data}

There were 670 observations each of wind direction, wind speed, temperature and relative humidity over the 10 days period. The frequency of the wind direction is presented in Table 3 . The frequency of wind directions ranged from SSE to WNW (157.5 degrees) with highest frequencies SW to WSW (45.0 degrees). Figure 2 shows the shape and direction of the plume for various periods of measurement.

Other weather variables that were measured included wind speed, temperature and relative humidity. The description of these variables is presented in Table 4. A scatter plots of the odour strength against these weather variables (wind speed, temperature and relative humidity) no correlation. However the wind speed measured at the source correlated well with how far the plume travelled along the centre line of the direction of wind. This tells predicting the effect of temperature and relative humidity at source of odour on downwind odour strength can be misleading. However, there was a strong inverse correlation between relative humidity and temperature ( $\mathrm{R}=-0.981$ ) where as there was no correlation between wind speed and the other two variables (relative humidity and temperature). Many factors have been reported to affect the degree to which odours form a source will impact a community, such as distance from receiver, and meteorological conditions, including ambient temperature, wind speed and wind direction [14].

Table 3. Frequency distribution of wind direction.

\begin{tabular}{ccccc}
\hline Wind Direction $(\mathbf{N}=\mathbf{6 7 0})$ & Frequency & Percent & $\begin{array}{c}\text { Cumulative } \\
\text { Frequency }\end{array}$ & Cumulative Percent \\
\hline E & 1 & 0.1 & 1 & 0.1 \\
ENE & 1 & 0.1 & 2 & 0.3 \\
SE & 1 & 0.1 & 3 & 0.4 \\
ESE & 3 & 0.4 & 6 & 0.9 \\
N & 3 & 0.4 & 9 & 1.3 \\
NNE & 6 & 0.9 & 15 & 3.2 \\
NE & 10 & 1.5 & 25 & 5.5 \\
NNW & 12 & 1.8 & 37 & 7.6 \\
NW & 14 & 2.1 & 51 & 9.9 \\
SSE & 15 & 2.2 & 66 & 15.4 \\
WNW & 37 & 5.5 & 103 & 23.7 \\
S & 56 & 8.4 & 159 & 35.4 \\
W & 78 & 11.6 & 237 & 49.0 \\
SSW & 91 & 13.6 & 328 & 74.2 \\
SW & 169 & 25.2 & 497 & 100.0 \\
WSW & 173 & 25.8 & 670 &
\end{tabular}


Table 4. Descriptive statistics of weather variables.

\begin{tabular}{cccc}
\hline Statistic $(\mathbf{N}=\mathbf{6 7 0})$ & Temperature $\left({ }^{\circ} \mathbf{C}\right)$ & Wind Speed $(\mathbf{m} / \mathbf{s})$ & Relative Humidity $(\%)$ \\
Mean & 28.47 & 0.83 & 75.14 \\
Median & 29.10 & 0.80 & 72.55 \\
SD & 2.69 & 0.527 & 11.93 \\
Range & 11.20 & 2.60 & 45.50 \\
Minimum & 22.80 & 0.00 & 53.90 \\
Maximum & 34.00 & 2.60 & 99.40 \\
\hline
\end{tabular}

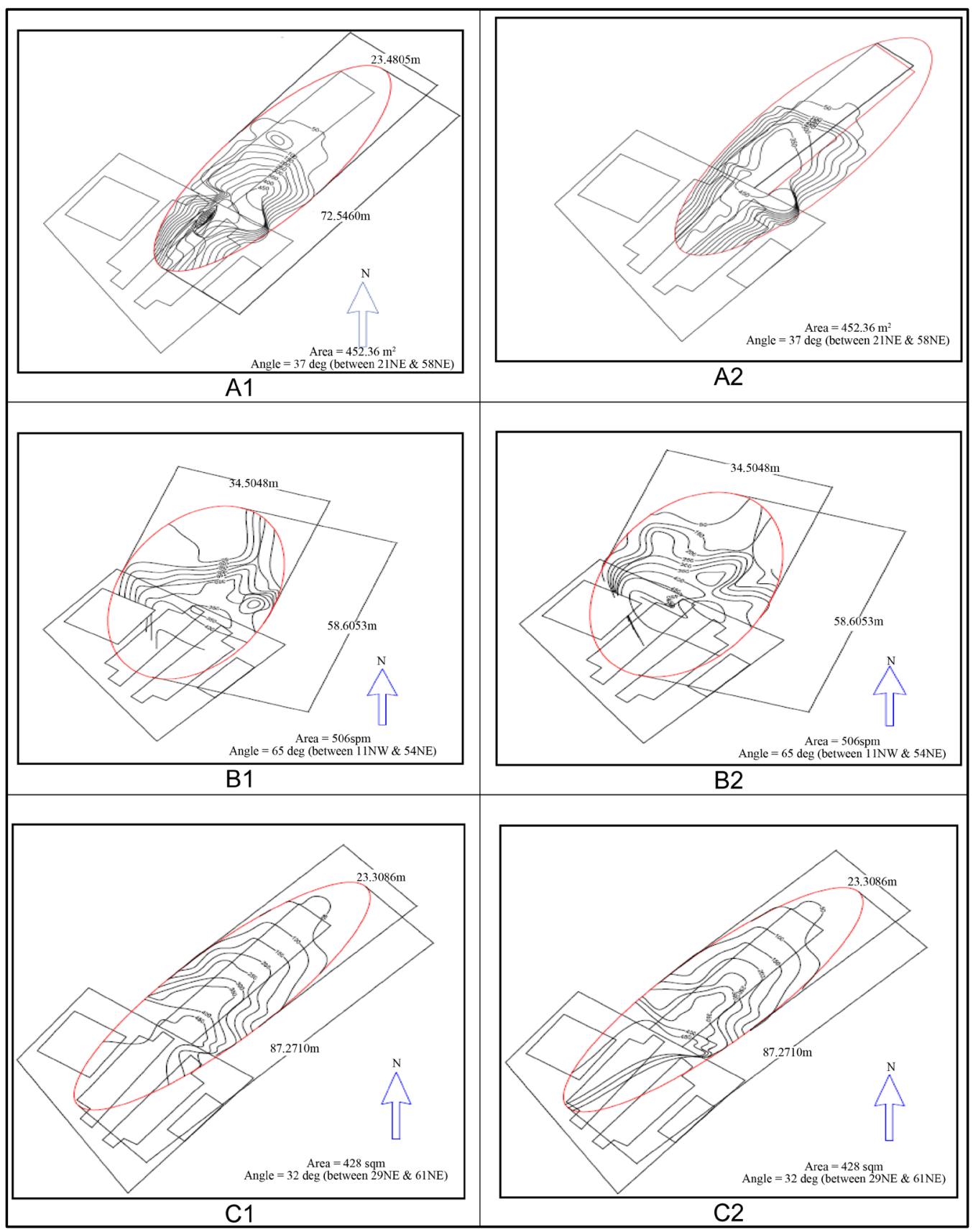

Figure 2. Shape and direction of plume for various periods of measurement (A’s-Morning, B's-Afternoon and C's-Evening). 


\subsection{Measurement of Odour Concentration with Nasal Ranger}

There were 175 odour strength measurements made over the 10 days period. These measurements were taken at various distances within the identified plume. Figure 2 shows a contour plot of odour strength within a plume at various periods of the day. 160 of the 175 odour strength measurements were greater than $7 \mathrm{OU} / \mathrm{m}^{3}$. Though there are no standards for ambient odour in Ghana, ambient odour ranging from $15 \mathrm{OU} / \mathrm{m}^{3}$ and more was considered by the trained inspectors as offensive. A regression analysis carried out showed a strong inverse correlation between odour strength and distance from source and $66.6 \%$ of the total variation in odour strength can be explained by distance from the source $\left(\mathrm{R}=-0.816, \mathrm{R}^{2}=0.666\right)$. With the possibility of establishing a regression model between odour strength and distance, the minimum distance of toilet facility from inhabitants can be determined can be determined before siting the facility.

\subsection{Model Simulation and Comparison with Measured Data}

As discussed earlier, the input to the dispersion model which is a mathematical simulation of the physics of the atmosphere consist of emission information, meteorological data and receptor information. The output from the model is the maximum concentration at specified distances as shown in Figure 3. The results of the field odour measurement (also shown in Figure 3) were compared with the results of the odour dispersion simulation by dispersion modelling. A paired t-test, $t(5)=-1.29, \mathrm{p}=0.902(\mathrm{p}>0.05)$, showed that there is no statistically significant difference between simulated model output and measured data. The results of the odour dispersion simulation can therefore be used to suggest improvements in the design of the toilet facility in relation to odour impacts.

\section{Conclusion}

In this study, modelling of the measurement events at specific receptor locations is compared to field odor measurements at the same locations. The model results have been compared to field odor measurements. Approximately model results fitted quite well with measured odor generally fall within the range of modeled values. A number of observations, however, exceed modelled values. This may be due to the uncertainty and assumptions made in the key inputs (emission rates, winds, release type, and stability); uncertainty in locating the observation point relative to the plume centerline, which is mainly a function of uncertainty in mean wind direction. Finally, the study amongst other things shows how perceived odour can be quantified objectively with the use of the Nasal Ranger Field Olfactometer through a consistent and standardized odour monitoring program. It also shows how results of such field measurements can be used to validate and odour dispersion model.

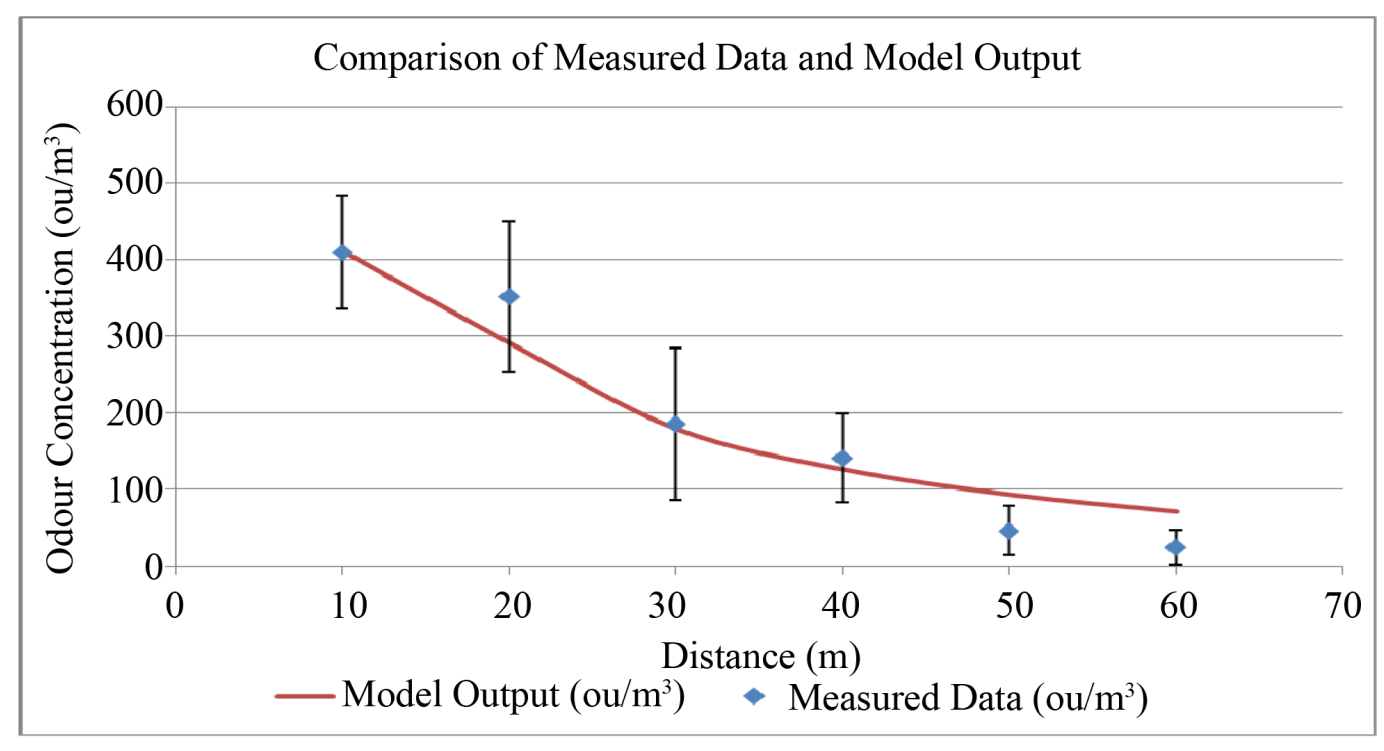

Figure 3. Comparison between simulated model output and measured data. 


\section{Acknowledgements}

This study was financed by the Bill and Melinda Gates Foundation under the SaniUp Project.

\section{References}

[1] Balling, R.C. and Reynolds, C.E. (1980) Evaluating Odor Reduction Technologies: Model. Journal of the Environmental Engineering Division, 106, 901-906.

[2] Hobson, J. (1995) The Odour Potential: A New Tool for Odour Management. Water and Environment Journal, 9, 458463. http://dx.doi.org/10.1111/j.1747-6593.1995.tb01483.x

[3] Stordeur, R., et al. (1981) A New Microprocessor-Controlled Dynamic Olfactometer. Journal of the Air Pollution Control Association, 31, 377-380. http://dx.doi.org/10.1080/00022470.1981.10465232

[4] Clarkson, C. (1993) Odour Taken to Task at WWT Plants. Water Wastewater Treatment, 36, 44.

[5] Schulz, T. and Van Harreveld, A. (1996) International Moves towards Standardisation of Odour Measurement Using Olfactometry. Water Science and Technology, 34, 541-547. http://dx.doi.org/10.1016/0273-1223(96)00594-X

[6] Rheinländer, T., et al. (2013) Smell: An Overlooked Factor in Sanitation Promotion. Waterlines, 32, 106-112. http://dx.doi.org/10.3362/1756-3488.2013.012

[7] Evans, B., et al. (2010) Hooked on Sanitation Subsidies. Reaching the MDG Target for Sanitation in Africa—A Call for Realism. Danish Ministry of Foreign Affairs.

[8] Jenkins, M.W. and Curtis, V. (2005) Achieving the "Good Life”: Why Some People Want Latrines in Rural Benin. Social Science \& Medicine, 61, 2446-2459. http://dx.doi.org/10.1016/j.socscimed.2005.04.036

[9] Jenkins, M.W. and Scott, B. (2007) Behavioral Indicators of Household Decision-Making and Demand for Sanitation and Potential Gains from Social Marketing in Ghana. Social Science \& Medicine, 64, 2427-2442. http://dx.doi.org/10.1016/j.socscimed.2007.03.010

[10] van der Geest, S. (2007) Not Knowing about Defecation. On Knowing \& Not Knowing in the Anthropology of Medicine. Berg, Oxford, 75-86.

[11] Capelli, L., et al. (2013) Measuring Odours in the Environment vs. Dispersion Modelling: A Review. Atmospheric Environment, 79, 731-743. http://dx.doi.org/10.1016/j.atmosenv.2013.07.029

[12] Lin, J., et al. (2013) Qualitative and Quantitative Analysis of Volatile Constituents from Latrines. Environmental Science \& Technology, 47, 7876-7882. http://dx.doi.org/10.1021/es401677q

[13] Afful, K., Oduro-Kwarteng, S. and Awuah, E. (2015) Assessing Public Perception of Odours in a Community: Case of Ayigya Zongo, an Urban Poor Community in Ghana. Journal of Water, Sanitation and Hygiene for Development, 5, 244-251. http://dx.doi.org/10.2166/washdev.2015.104

[14] Dalton, P., et al. (2011) A Multi-Year Field Olfactometry Study near a Concentrated Animal Feeding Operation. Journal of the Air \& Waste Management Association, 61, 1398-1408. http://dx.doi.org/10.1080/10473289.2011.624256 